\title{
Comparison of the efficacy of four endobronchial ablation techniques in dogs
}

\author{
LINRONG TONG ${ }^{1,2}$, KOUDONG ZHANG $^{3}$, HAIDONG HUANG $^{2}$, WEI ZHANG ${ }^{2}$, \\ XINGXING ZHANG ${ }^{2}$, QIN WANG ${ }^{2}$, QIANG $\mathrm{LI}^{2}$ and $\mathrm{CHONG} \mathrm{BAI}{ }^{2}$ \\ ${ }^{1}$ Department of Respiratory Medicine, Xiamen 174 Hospital, Xiamen, Fujian 361000; \\ ${ }^{2}$ Department of Respiratory Medicine, Changhai Hospital, Shanghai 200433; \\ ${ }^{3}$ Department of Respiratory Medicine, Yancheng City First People's Hospital, Yancheng, Jiangsu 224000, P.R. China
}

Received March 24, 2015; Accepted August 23, 2016

DOI: $10.3892 / \mathrm{etm} .2016 .3946$

\begin{abstract}
The present study aimed to evaluate the safety and efficacy of four commonly used ablation techniques, namely neodymium-doped yttrium aluminium garnet (Nd:YAG) laser therapy, argon plasma coagulation (APC), high-frequency electrocautery and $\mathrm{CO}_{2}$ cryotherapy. The techniques were performed at various powers or impedance settings, and for various durations, on the trachea of beagle dogs. Pathological changes of the tracheal wall were assessed by bronchoscopy. The endoscopic gross appearance of lesions induced by ablation treatments was consistent with the histopathological changes. The results suggested that cryotherapy was relatively safe, whereas APC induced superficial tissue coagulative necrosis. Furthermore, Nd:YAG laser therapy was the most efficient technique and showed the greatest penetration potential. In general, tissue injury was exacerbated with extended application time, at constant power or impedance. The safest application parameters were $20 \mathrm{~W}$ for $\leq 1 \mathrm{sec}$ for Nd:YAG laser therapy, $40 \mathrm{~W}$ for $\leq 3 \mathrm{sec}$ for electrocautery, $40 \mathrm{~W}$ for $\leq 5 \mathrm{sec}$ for APC and $100 \Omega$ for $\leq 120 \mathrm{sec}$ for cryotherapy. At the maximum times, these settings resulted in identical pathological changes. Healing of the lesions following ablation was achieved within 3 weeks. The Nd:YAG laser, APC, electrocautery and cryotherapy endobronchial ablation techniques differed according to their potential and limitations for application on the trachea. However, when applied at specific combinations of power or impedance and duration, they exhibited similar efficacies.
\end{abstract}

Correspondence to: Dr Chong Bai, Department of Respiratory Medicine, Changhai Hospital, 168 Changhai Road, Shanghai 200433, P.R. China

E-mail: bc7878@sohu.com

Key words: bronchoscopy, neodymium-doped yttrium aluminium garnet laser, argon plasma coagulation, electrocautery, $\mathrm{CO}_{2}$ cryotherapy

\section{Introduction}

The diagnosis and treatment of pulmonary diseases has markedly improved with advances in the technologies of interventional pulmonary medicine (1-4). For example endobronchial ablation techniques have been employed in the treatment of intraluminal diseases of the tracheobronchial tree $(5,6)$. The viability of these technologies for the curative treatment of airway obstructions caused by benign lesions, including benign tumors, endobronchial tuberculosis and granulomatosis, has been established (7). They are also important in the palliative treatment of patients with late-stage lung cancers (8). In China, the bronchoscopic ablation techniques commonly used include neodymium-doped yttrium aluminium garnet ( $\mathrm{Nd}: \mathrm{Y}_{3} \mathrm{Al}_{5} \mathrm{O}_{12}$, or $\left.\mathrm{Nd}: \mathrm{YAG}\right)$ laser therapy, high-frequency electrocautery, argon plasma coagulation (APC) and $\mathrm{CO}_{2}$ cryotherapy (9-11). These techniques may be performed via rigid or flexible fiberoptic bronchoscopy.

Among the malignant tumors, lung cancer has been ranked first in the world in terms of its morbidity and mortality (12). The majority of patients with lung cancer present at the late stage, when curative surgical resection is not an option, and $30 \%$ have obstructions in the trachea or main bronchi (13). For these patients, endobronchial therapy can restore airway patency, alleviate dyspnea, preserve quality of life, improve survival rates and allow further treatments, such as external beam radiation, chemotherapy and surgery (14).

The detection rate for bronchogenic carcinomas in situ and early-stage intraluminal carcinomas has improved with technological developments $(15,16)$. Patients who suffer from superficial lesions, but are inoperable due to an unfit health status, can be treated by bronchoscopic interventions to prevent progression to invasive cancer (17). For these patients, the first choice for palliation or treatment with curative intent is currently photodynamic therapy (18). However, the availability of photodynamic therapy is limited at most institutions in China because of its expense and the cumbersomeness of the equipment. Instead, endobronchial ablation utilizing Nd:YAG laser therapy, electrocautery, APC or cryotherapy are typically used because of their lower cost, portability and comparable efficacy (11). However, long-term observational studies and prospective randomized controlled trials are necessary for definitive verification of these techniques (19). 
China initially lagged behind developed countries in adopting interventional pulmonary medicine, and a disparity still exists. In some parts of the country, the availability of ablation technologies remains very limited and there is the question of whether purchasing one or two of these would suffice and be comparable to an entire set of the latest equipment. There is a relative paucity of data to differentiate the various endobronchial ablation technologies according to their biological effects, efficacy and safety with specific applications. In addition, the healing course of lesions induced by endobronchial ablation is not known.

In a preliminary in vitro study, the authors of the present study evaluated several endobronchial coagulation techniques (microwave, APC, electrocautery and cryotherapy) and determined specific values for technical parameters associated with their safety and efficacy (20). In the present study, the efficacy of Nd:YAG laser therapy, electrocautery, APC and $\mathrm{CO}_{2}$ cryotherapy in dogs was evaluated, to determine their relative merits and the optimal technical parametric values for clinical practice.

\section{Materials and methods}

Animals and pre-tracheal ablation procedures. The present study was approved by the Institutional Animal Research Ethics Committee. A total of 6 healthy adult beagle dogs (3 male and 3 female) weighing 10-12 kg were provided by the Laboratory Animal Center at the Second Military Medical University (Shanghai, China). The beagle dogs were bred under normal room conditions at a temperature of $16-26^{\circ} \mathrm{C}$, humidity of 40-70\%, noise level $<60 \mathrm{~dB}$, and 100-200 lux illumination. Adequate drinking water was provided. The daily quantity of food was approximately $3-5 \%$ of the dog weight. The food was divided into two portions; one was provided in the morning, and the other was provided in the afternoon.

General anesthesia was induced using intravenous amobarbital sodium $(0.1 \mathrm{ml} / \mathrm{kg}$; Shanghai Xinya Pharmaceutical Co. Ltd., Shanghai, China), and 2\% lidocaine (Jincheng Hayes Pharmaceutical Co., Ltd., Jincheng, China) was administered onto the tracheal mucosa. Following anesthetization, the dogs were placed in the supine position with the head and limbs fixed on the operating bench.

Using a laryngoscope blade and an intubation stylet, with the tongue displaced to the left, the blade was introduced with its concave surface directed ventrally and the soft palate was displaced dorsally to reveal the rima glottidis. Subsequently, the intubation stylet was advanced beyond the level of the vocal folds and the trachea was intubated $(7.5-\mathrm{mm}$ internal diameter tracheal tube). The mouth was kept open with a bite blocker, and the tongue was extended and secured with a strip of gauze tied to the bite blocker.

An Olympus T260 Fiberoptic Bronchoscope (Olympus Corporation, Tokyo, Japan) was introduced into the trachea and the tracheobronchial tree was examined. The middle and lower parts of the trachea, excluding the membranous part, were selected as the target tissue for the ablation treatments. During the bronchoscopy, mucous secretions were removed directly through negative pressure suction when required. Each dog underwent four endobrachial ablation procedures, as described in the following sections.
Nd:YAG laser ablation. A LaserPro 810 Laser Probe (Collin SAS, Bagneux, France) was inserted through the working channel of the bronchoscope, and advanced at least $1 \mathrm{~cm}$ beyond the distal end of the bronchoscope. With the aid of a pilot red light, the laser energy was focused on the target tissue; the tip of the probe was directed to the target tissue and was maintained at a distance of 4-10 $\mathrm{mm}$ from the tissue surface. Power was set at $20 \mathrm{~W}$, and was applied with a pulse of 1,2 or $3 \mathrm{sec}$ (setting on the equipment) at three separate sites at $2-\mathrm{cm}$ intervals.

High-frequency electrocautery. An electrocautery probe $\left(\mathrm{VIO}^{\circledR} 300 \mathrm{D}\right.$; Erbe Elektromedizin GmbH, Tübingen, Germany) was passed through the working channel of the bronchoscope, and protruded 1-2 $\mathrm{cm}$ beyond the distal end of the bronchoscope. The probe was placed in contact with the target site, and an electric current, with the power set at $40 \mathrm{~W}$, was applied for 1,3 or $5 \mathrm{sec}$ at three separate sites at $2-\mathrm{cm}$ intervals.

APC ablation. The APC probe $\left(\mathrm{VIO}^{\circledR} 300 \mathrm{D}\right)$ was inserted through the working channel of the bronchoscope, and advanced $1 \mathrm{~cm}$ beyond the distal end of the bronchoscope, with the tip of the probe held 4-10 $\mathrm{mm}$ from the target tissue. APC was performed with an argon flow rate of $21 / \mathrm{min}$ and a power of $40 \mathrm{~W}$, with a burst of 1,3 or $5 \mathrm{sec}$ at three separate sites at 2-cm intervals.

Cryotherapy ablation. Cryotherapy (K300 Cryosurgery Equipment; Beijing Kooland Technology, Co., Ltd., Beijing, China) was performed by passing a cryoprobe through the flexible bronchoscope until it had advanced $1 \mathrm{~cm}$ beyond the distal end of the bronchoscope. The tip of the cryoprobe was kept in contact with the tracheal mucosa. Three freeze-thaw cycles, with the impedance set at $100 \Omega$, were applied at two separate sites (at a 2 -cm interval), with each freeze-thaw cycle lasting 60 or $120 \mathrm{sec}$.

Post-ablation protocol. Two dogs were sacrificed immediately following the endobronchial ablations to evaluate early pathological changes of the tracheal wall. Sacrifice was conducted by the intravenous injection of $0.1 \mathrm{ml} / \mathrm{kg}$ pentobarbital sodium, after which the femoral artery and vein in the femoral triangle area were cut out to induce exsanguination. The general health status of the remaining four dogs was monitored daily, including eating and physical activities, with special attention to respiratory complications and accidental death, until they were randomly sacrificed on days 3, 7, 14 or 21 postoperatively. The trachea with the injured sites was removed, divided into tissue blocks $(10 \times 10 \mathrm{~mm})$ and rinsed with normal saline. Subsequently, the specimens were fixed in formalin for $24 \mathrm{~h}$, embedded in paraffin, step-sectioned into 3- $\mu \mathrm{m}$ slices and stained with hematoxylin and eosin for analysis under a light microscope.

Evaluation of the biological effects of endobronchial interventions. Assessment of the biological effects of the ablation techniques was based on endoscopic gross findings and histopathological examinations. During the bronchoscopic interventions, the gross endoscopic changes within the tracheal lumen were recorded. These involved changes in the local 
mucosal color and texture, and the extent of injuries, including necrosis, carbonization, vaporization and perforation.

The tracheal tissue sections were observed under a light microscope to evaluate the histopathological changes of the mucosa, submucosa and cartilage layer. The severity of injuries was defined as mild $(+)$, moderate $(++)$ or severe $(+++)$, according to the extent of the injured area. The maximal depths and dimensions of tissue damage were measured in the central area of the lesions in step sections. The actual measurements were performed using a Vernier caliper (Fig. 1).

\section{Results}

Gross appearance of the trachea following endobronchial ablation. Gross alterations of the trachea of the dogs following the four types of endobronchial ablations were observed by bronchoscopy. In general, immediate alterations included desiccation of the mucosal surface, a whitish or charred yellow coagulation spot and hardening of the injured area. Over time, the area of coagulation expanded to become a crater-shaped lesion. The surrounding area and bottom of the lesion were covered with charred eschar, sometimes with perforation.

Laser-induced tracheal injury had a sharp edge (Fig. 2), while injuries induced by high-frequency electrocautery or APC had no sharp boundaries (Fig. 2). The severity of injury positively correlated with the application time. Cryotherapy-induced injury had markedly less obvious tissue defect compared with the other ablation techniques. When $100 \Omega$ impedance was applied for $60 \mathrm{sec}$, whitish mucosa, edema and hardening of the tissue were observed. When applied for $120 \mathrm{sec}$, these changes were more obvious and the integrity of the mucosa was destroyed (Fig. 2). Normal tracheal mucosa on gross endoscopic examination showed a smooth mucosal surface, clearly visible vessels and cartilage rings (Fig. 2).

Histopathological alterations of the trachea following endobronchial ablations. Histopathological alterations of the trachea following all four types of endobronchial ablations in the dogs included epithelial and submucosal necrosis and shedding, as well as destruction and perforation of the cartilage layer (Fig. 3). The severity of injuries correlated with the application time of ablation. Notably, the histopathological changes were consistent with the endoscopic gross appearances of the tracheal lumen.

To compare the safety and efficacy of the four types of ablative techniques, the depths and dimensions of tracheal injuries, and the severity of tissue necrosis and cartilage damage, induced by the different methods were examined (Table I). The histopathological changes of the tracheal wall induced by these various ablation techniques varied according to the parametric settings and application times (Table I; Fig. 3). The parametric settings included the power output (W for Nd:YAG laser, APC and electrocautery) or impedance ( $\Omega$ for cryotherapy).

When the 20-W laser was applied for $1 \mathrm{sec}$, histopathological changes of the tracheal injury included mucosal necrosis and submucosal coagulative necrosis, which extended deep into the surface of the cartilage (Fig. 3). When the application time was extended to $2 \mathrm{sec}$, two-thirds of the cartilage layer was destroyed, accompanied by apparent coagulative necrosis in the surrounding tissue (Fig. 3). Furthermore, following

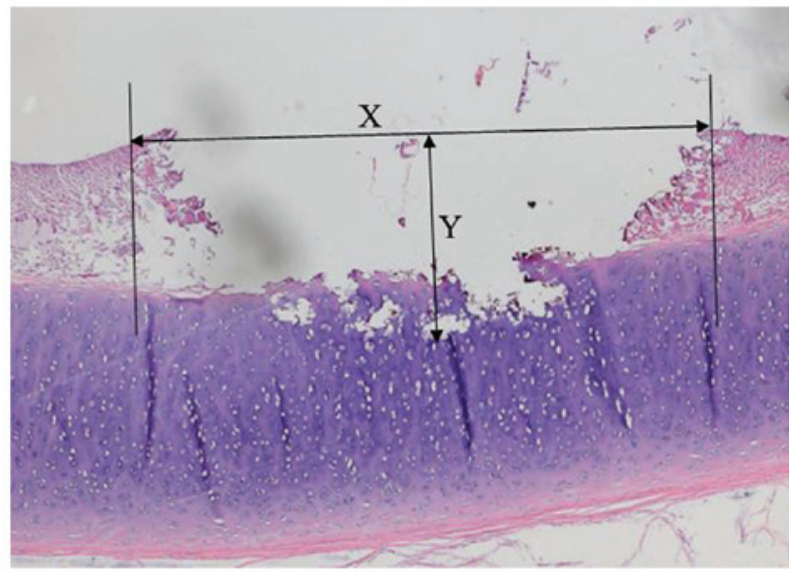

Figure 1. Representative image showing measurement of the dimensions (width and depth) of a tracheal injury with tissue coagulative necrosis and damage (magnification, $4 \mathrm{x} 10$ ). $\mathrm{X}$ is the maximal width of the central area affected; $\mathrm{Y}$ is the maximal depth of the defect, from the surface of the mucosal epithelium to the deepest tissue affected.

application of $20 \mathrm{~W}$ for $3 \mathrm{sec}$, a transmural tracheal defect was observed at the center of the injury and coagulative necrosis in the surrounding tissue was more severe, with perforation of the tracheal wall (Fig. 3). The injuries induced by high-frequency electrocautery and APC were similar to those induced by laser therapy, and the severity of injuries also correlated with the application time of each technique (Fig. 3).

Cryotherapy-induced injury showed no apparent necrosis. However, mucosal and epithelial shedding and thromboembolism formation was observed. The cartilage layer remained intact (Fig. 3). Histological analysis of the normal tracheal wall under an optical microscope showed three layers of structure (from top to bottom): mucosa, submucosa and adventitia (Fig. 3).

Parametric settings and application times that allow equivalent efficacy of the four endobronchial ablation techniques. To identify the settings for the four types of endobronchial ablation techniques that achieved similar efficacies in the dog trachea, the histopathological changes and the depths of injuries induced by each type were compared (Table II). The following settings had equivalent effects on the tracheal wall: $20 \mathrm{~W}$ for $1 \mathrm{sec}$ for Nd:YAG laser therapy; $40 \mathrm{~W}$ for $1 \mathrm{sec}$ for electrocautery; $40 \mathrm{~W}$ for $5 \mathrm{sec}$ for APC; and $100 \Omega$ for $120 \mathrm{sec}$ for $\mathrm{CO}_{2}$ cryotherapy. The histological characteristics of tracheal injuries under these settings included mucosal necrosis and shedding, submucosal coagulative necrosis and an intact cartilage layer. The depth of injury was $<2 \mathrm{~mm}$.

Tissue repair and healing following endobronchial interventions. Changes of tracheal injuries induced by the four endobronchial ablation techniques over time were similar, and could be considered to occur in four phases, including acute injury, inflammation, repair and healing (Fig. 4). The acute phase consisted of pathological changes characterized by desiccation of the mucosal surface, a whitish or charred yellow coagulation spot and hardening of the injured areas (Fig. 3).

The inflammatory phase of injury was evident on day 3 following the procedure, and was characterized by hyperemia 
Nd:YAG laser
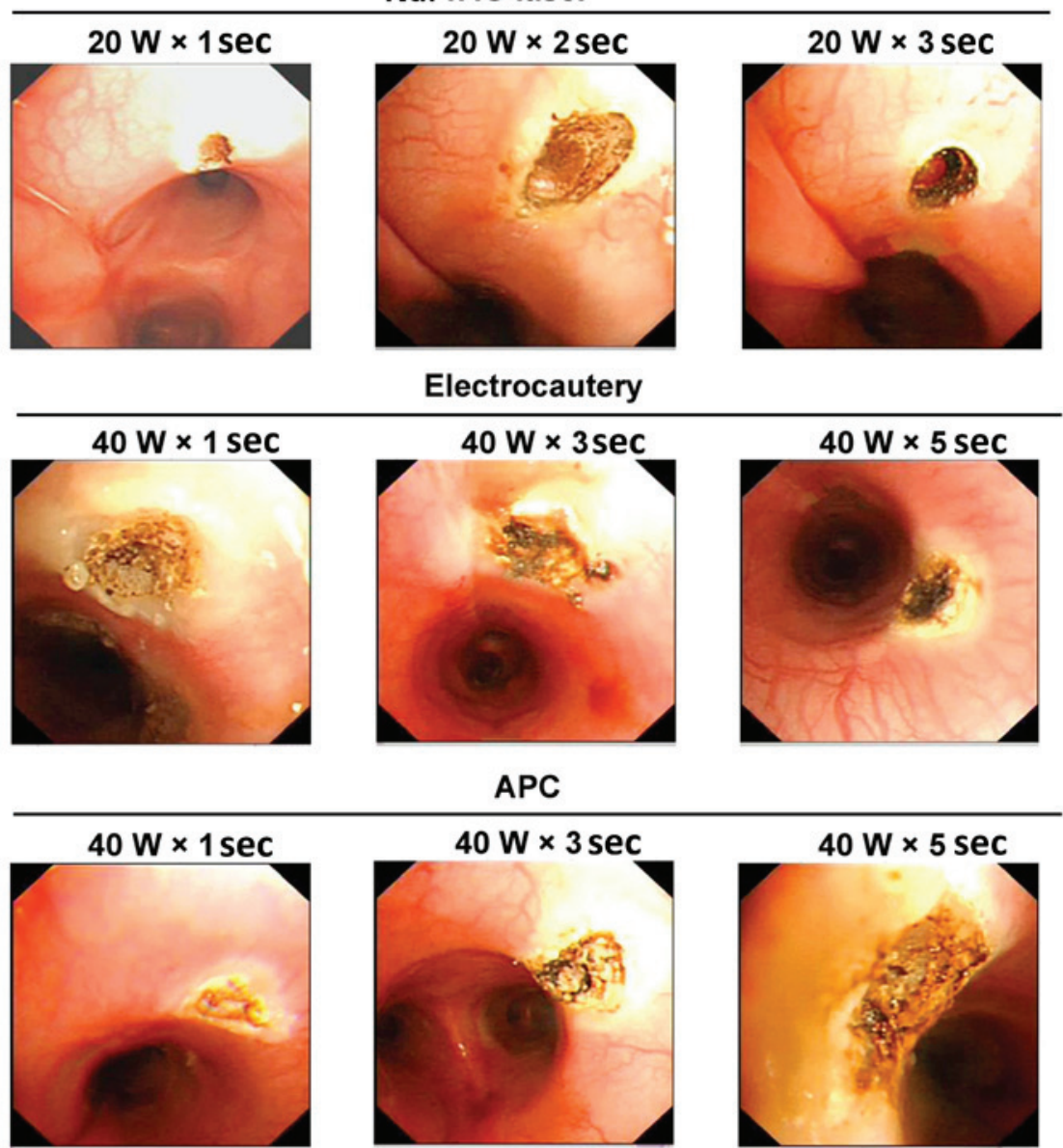

$40 \mathrm{~W} \times 3 \mathrm{sec}$

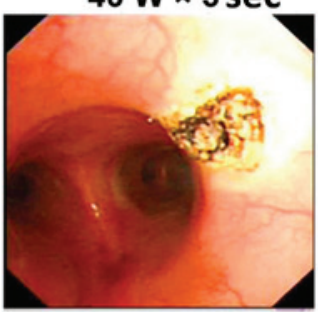

$40 \mathrm{~W} \times 5 \mathrm{sec}$

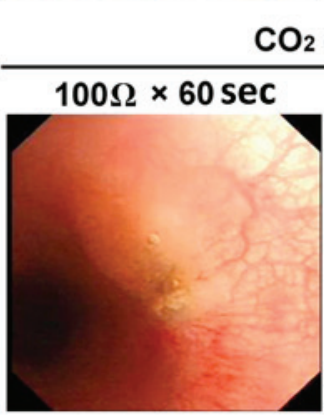

$\mathrm{O}_{2}$ cryotherapy
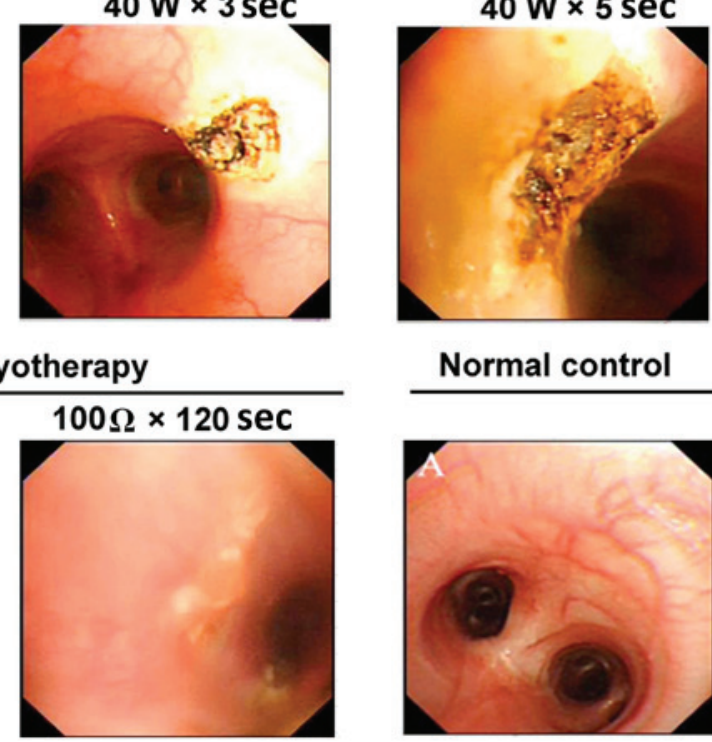

\section{Normal control}

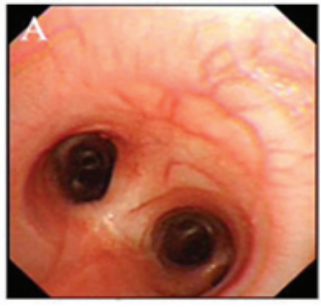

Figure 2. Representative images of the gross appearance of the tracheal lumen of dogs following various endobronchial ablation therapies. Nd:YAG laser: 1 sec, mucosal carbonation and local cavity formation; $2 \mathrm{sec}$, volcano-shaped wound with black carbonized tissue at the bottom and surrounding areas; 3 sec, further deepening of the wound, with increased tissue carbonization and vaporization. Electrocautery: $1 \mathrm{sec}$, tracheal wall whitening with a slightly sunken, yellow central focus, a small area of injury with a clear boundary and no obvious tissue vaporization; $3 \mathrm{sec}$, increased coagulation spots around the central region, with tissue carbonization and vaporization in the center of the volcano-shaped injury; $5 \mathrm{sec}$, increased tissue carbonation and vaporization, a further deepened wound, and significantly increased black eschar. APC: $1 \mathrm{sec}$, yellow solidification spots, pale adjacent mucosa and no obvious tissue loss; 3 sec, larger coagulation spots, with a central depression and surface carbonization; $5 \mathrm{sec}$, further expanded area of solidification, a deepened central depression, and evident tissue carbonization. Cryotherapy: $60 \mathrm{sec}$, whitened mucosa, mucosal edema and tissue hardening; $120 \mathrm{sec}$, pale area of mucosal injury, evident mucosal edema and loss of mucosal integrity. W, watt; $\Omega$, ohm; Nd:YAG, neodymium-doped yttrium aluminium garnet laser therapy; APC, argon plasma coagulation.

and edema of the mucosa surrounding the injury, with the presence of tissue defect and necrotic debris. Furthermore, a large number of inflammatory cells were observed to have infiltrated into the injured areas (Fig. 4).

The repair phase was initiated on day 7 following the ablation treatments (Fig. 4). The hyperemia and edema of the mucosa surrounding the lesion gradually subsided. In addition, the tissue defect was replaced by the proliferation of a pseudostratified, columnar epithelium in the mucosa, granulation tissue with the infiltration of inflammatory cells and newly forming capillaries in the submucosa. The gap caused by tissue disruption was filled with granulation tissue.

The healing phase of injuries could be seen 2-3 weeks postoperatively (Fig. 4). The gross appearance of the lesion was similar to that of normal tissue, with no hyperemia and edema. Histopathological analyses showed a well-developed, pseudostratified columnar epithelium and proliferation of fibrous tissue, with fewer inflammatory cells in the submucosa. Fibrous tissue had replaced the damaged submucosa and cartilage to maintain the integrity of the tracheal wall. 
Nd:YAG laser
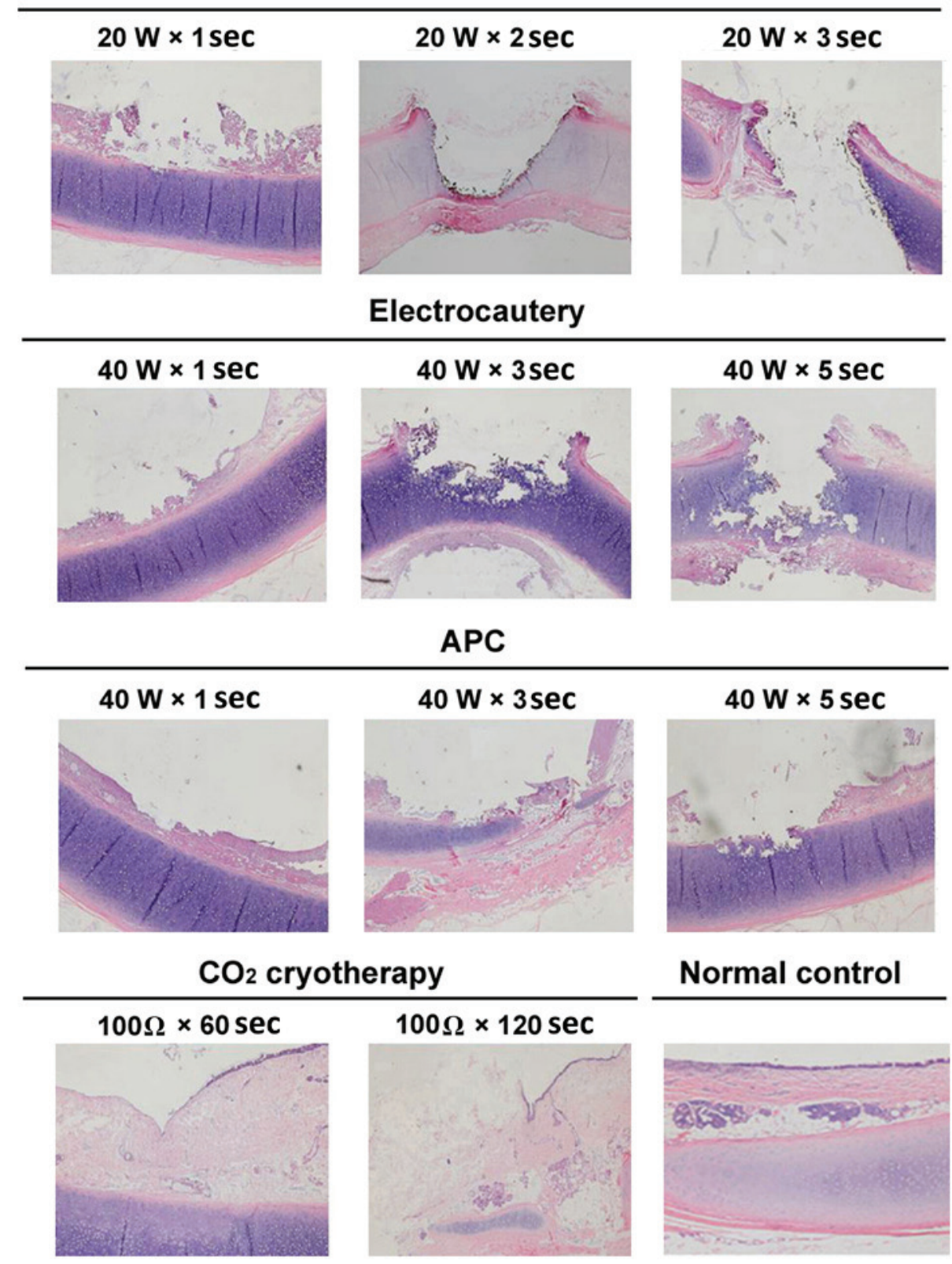

Figure 3. Representative images of histopathological changes of the tracheal mucosa of dogs following various endobronchial ablation therapies (hematoxylin and eosin staining, magnification, $\mathrm{x} 40$ ). Nd:YAG laser: $1 \mathrm{sec}$, mucosal necrosis and defect, with submucosal tissue necrosis at the surface of the cartilage; $2 \mathrm{sec}$, mucosal/submucosal defect and vaporization deeper into the cartilage, with damage affecting $>2 / 3$ of the cartilage, and obvious surrounding tissue necrosis; $3 \mathrm{sec}$, tracheal wall defect and perforation in the central region, with increased necrosis of the surrounding tissue. Electrocautery: 1 sec, mucosal epithelial necrosis, and submucosal tissue necrosis affecting the cartilage layer; $3 \mathrm{sec}$, mucosal/submucosal necrosis deeper into the cartilage layer, with $1 / 2$ of the cartilage structure being destroyed; $5 \mathrm{sec}$, increased tissue necrosis, with damage and fracture of mucosa/submucosa and the cartilage layer, and airway perforation. APC: $1 \mathrm{sec}$, mucosal shedding and superficial submucosal necrosis; $3 \mathrm{sec}$, larger coagulation spots, a central depression and surface carbonization; $5 \mathrm{sec}$. mucosal defect, with submucosal tissue necrosis affecting the surface of the cartilage; the cartilage layer was slightly damaged but retained its integrity. Cryotherapy: $60 \mathrm{sec}$, epithelial cell shedding and local thrombosis, but no obvious tissue necrosis; $120 \mathrm{sec}$, mucous layer defect, disordered submucosal structure, and damage reaching to the surface of the cartilage layer; the cartilage structure was intact and local thrombosis was observed. W, watt; $\Omega$, ohm; Nd:YAG, neodymium-doped yttrium aluminium garnet laser therapy; APC, argon plasma coagulation.

\section{Discussion}

The present study evaluated the safety and efficacy of four commonly used endobronchial ablation techniques, which were applied via fiberoptic bronchoscopy to beagle dogs. The ablation techniques included Nd:YAG laser therapy, high-frequency electrocautery, APC and $\mathrm{CO}_{2}$ cryotherapy. The results of the study indicated that the biological effects on the trachea induced by each technique differed according to parametric settings (power or impedance) and application times. However, it was possible to achieve comparable efficacy and safety when these tools were applied at optimal settings and application times, which were specific to each technique. Furthermore, the repair and healing processes in the damaged trachea following these interventions were observed and described.

Ablation may be categorized as hot or cold therapy. The hot therapies, which include Nd:YAG laser therapy, high-frequency 


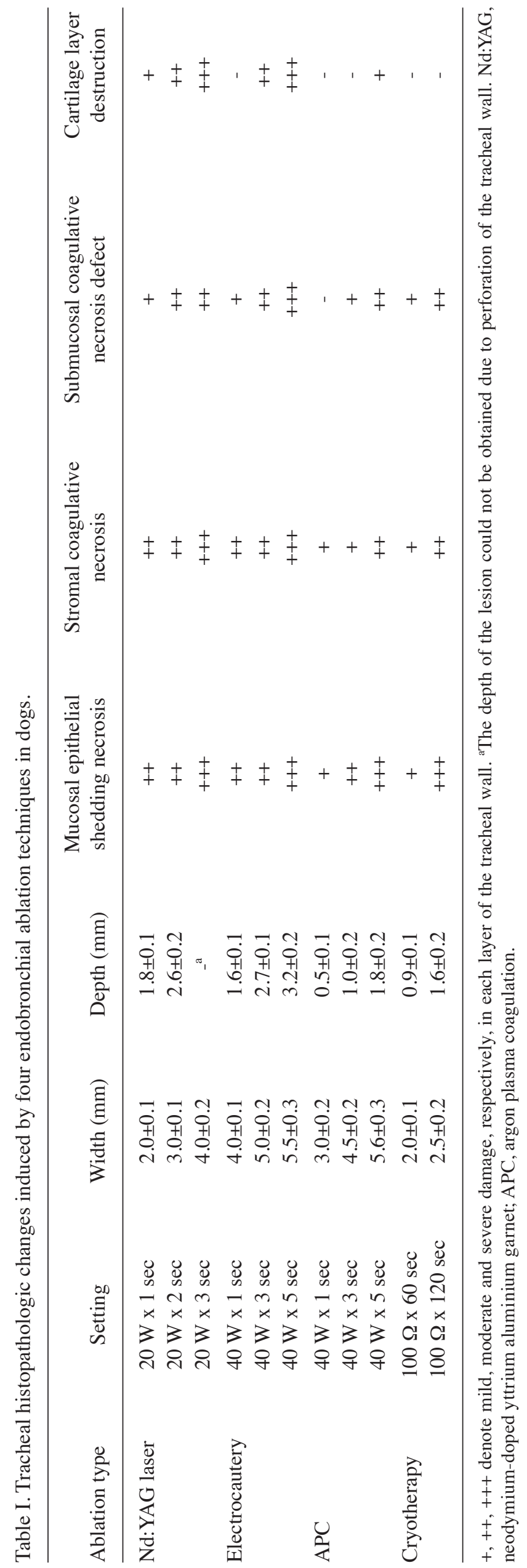

electrocautery and APC, produce and apply thermal energy to a tissue, causing immediate coagulative necrosis and tissue vaporization $(21,22)$. Conversely, the effect of cold therapies, including cryotherapy, is relatively delayed, with tissue necrosis appearing 2-3 days following the procedure (23-26). In the present study, the most common histopathological changes of the trachea wall among the various endobronchial ablation techniques were tissue coagulative necrosis and vaporization. However, the extent of tissue damage varied depending on the settings for power output (Nd:YAGlaser, APC and electrocautery) or impedance (cryotherapy), and application time.

Nd:YAG laser therapy was the most efficient ablation technique and resulted in immediate tissue coagulation, penetration, vaporization and transmural tracheal damage during treatment. The effect of high-frequency electrocautery was similar to Nd:YAG laser therapy. Electrocautery applied at $40 \mathrm{~W}$ for $3 \mathrm{sec}$ caused tissue vaporization that extended into half of the cartilage layer; after $5 \mathrm{sec}$ of application, the transmural tracheal wall was destroyed. APC induced more superficial coagulative necrosis and less vaporization compared with Nd:YAG laser therapy and electrocautery; when applied at $40 \mathrm{~W}$ for $5 \mathrm{sec}$, the cartilage layer was superficially damaged, but most of the deep structures in the cartilage remained intact. Although cryotherapy was superior in terms of safety and toleration by the bronchial wall, its effect was delayed. Cryotherapy applied at $100 \Omega$ for either 60 or $120 \mathrm{sec}$ did not affect the cartilage layer. These features were consistent with the results of previous studies $(5,6,23,24,26-31)$.

Based on our previous study (20) and clinical experience, the current study chose to assess Nd:YAG laser therapy at $20 \mathrm{~W}$, electrocautery and APC at $40 \mathrm{~W}$, and cryotherapy at $100 \Omega$. The results indicated that, at any power (or impedance) held constant, tracheal injury was exacerbated with application time. Mucosal coagulative necrosis can infiltrate into the submucosa and subsequently extend into the cartilage layer, resulting in airway perforation. This suggests that ablation may achieve the desired level of tissue damage if the duration of application is adjusted, which is useful, especially when treating carcinomas in situ, to reduce the risk of airway perforation. The results of the present study indicated that the ablation techniques can be applied safely when the following parameters are used: Nd:YAG laser therapy, $20 \mathrm{~W}$ for $\leq 1 \mathrm{sec}$; electrocautery, $40 \mathrm{~W}$ for $\leq 3 \mathrm{sec}$; APC, $40 \mathrm{~W}$ for $\leq 5 \mathrm{sec}$; and cryotherapy, $100 \Omega$ for $\leq 120 \mathrm{sec}$.

Nd:YAG laser therapy is the most commonly used endobronchial ablation technique because of the excellent coherence, monochromaticity and collimation of the laser $(5,28)$. However, Nd:YAG laser therapy should be performed with caution in clinical practice. To minimize the risk of airway perforation, the laser beam must always be parallel to the wall of the airway and not perpendicular to it, and the minimum effective power and shortest duration of application should be selected. Lai et al (27) found that the serum levels of interleukin-2 and natural killer cell activity were increased following Nd:YAG laser therapy, suggesting that laser therapy may enhance immunity, in addition to its thermal effect. Long-term studies of patients with late-stage lung cancer have shown that Nd:YAG laser therapy is able to effectively relieve symptoms, improve the quality of life and prolong survival $(28,32)$. 
Table II. Efficacy-equivalent settings of four endobronchial ablation techniques applied to the trachea of dogs.

\begin{tabular}{lccc}
\hline Ablation type & Setting & Onset of effects & Depth of lesion (mm) \\
\hline Nd:YAG laser & $20 \mathrm{~W} \times 1 \mathrm{sec}$ & Immediate & $1.8 \pm 0.1$ \\
Electrocautery & $40 \mathrm{~W} \times 1 \mathrm{sec}$ & Immediate & $1.6 \pm 0.1$ \\
$\mathrm{APC}$ & $40 \mathrm{~W} \times 5 \mathrm{sec}$ & Immediate & $1.8 \pm 0.2$ \\
$\mathrm{CO}_{2}$ cryotherapy & $100 \Omega \times 120 \mathrm{sec}$ & Delayed & $1.6 \pm 0.2$ \\
\hline
\end{tabular}

Nd:YAG, neodymium-doped yttrium aluminium garnet; APC, argon plasma coagulation.

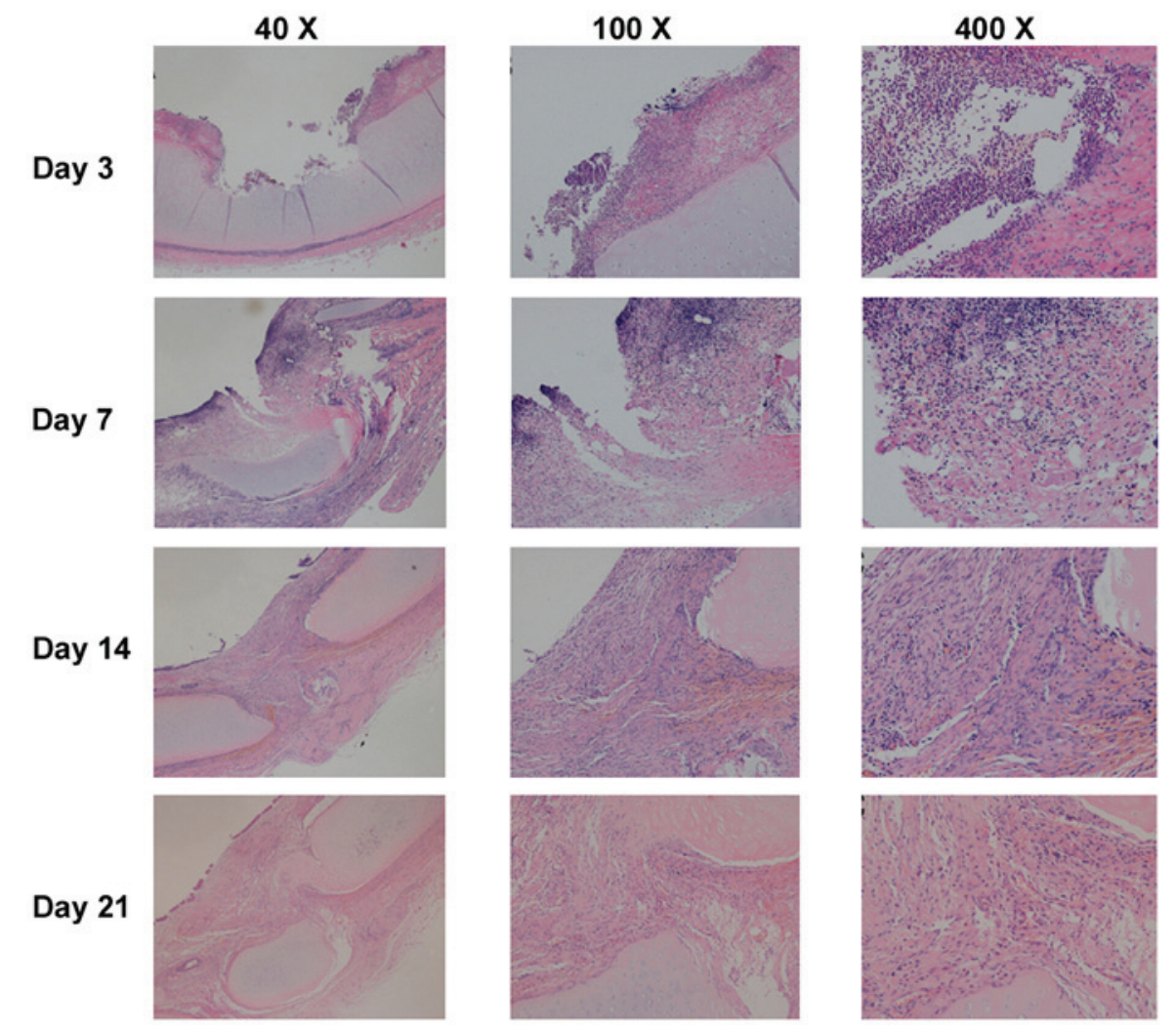

Figure 4. Representative images of histological changes of the tracheal mucosa on days 3, 7, 14 and 21 following endobronchial ablation in dogs (hematoxylin and eosin staining). The tracheal wall repair process was similar following the four different ablation techniques, with four stages: Acute injury, inflammation, repair and healing. On day 3 (inflammatory stage), tissue defects were present with a small amount of necrotic tissue, mucosal hyperemia and edema, and inflammatory cell infiltration. On day 7 (tissue repair stage), mucosal hyperemia and edema around the injury were decreased and the defect area was filled with hyperplastic tissue. Pseudostratified columnar epithelium hyperplastic tissue incompletely covered the damaged region, and submucosal granulation tissue was rich with new capillaries. Tissue defects were filled with granulation tissue, and inflammatory cells infiltrated the granulation tissue. On days 14 and 21 (healing stage), the mucosa in the injured area was similar to normal mucosa without obvious hyperemia and edema. Pseudostratified columnar epithelium grew well, with fibrous tissue hyperplasia, and submucosal glands decreased significantly compared with normal tissue. Inflammatory cell content gradually reduced, and the destroyed submucosa and cartilage were repaired with fibrous tissue, which maintained the integrity of the tracheal wall.

As a thermal ablation technique, high-frequency electrocautery transforms electrical energy into thermal energy to remove lesions. It generally results in coagulative necrosis at low temperatures, and tissue vaporization and carbonization at high temperatures, with the focus on damaged tissue at the surface of contact $(29,31)$. In the present study, the extent of tracheal damage caused by electrocautery applied at $40 \mathrm{~W}$ was positively associated with the duration of application. The biological effects of electrocautery on tissue are dependent on various factors, including the nature of lesions, the current waveform, the power output, the duration of contact, the mode of application and the type of probe $(29,31,33)$. Local blood flow and mucosal secretion are also thought to influence the efficacy of electrocautery (34). In the present study, the influence of the local mucosa was excluded, since normal trachea was selected as the target tissue and mucosal secretion could be easily and rapidly removed during the procedure; Our results indicated that the extent of tissue damage was primarily associated with the duration of ablation. Considering the risk of airway perforation as a complication, we recommend that electrocautery be applied with a power setting of $40 \mathrm{~W}$ for $<3 \mathrm{sec}$ to ensure safety.

In the present study, it was observed that tissue penetration was limited using APC and, thus, the risk of airway 
perforation associated with this technique was less compared with the other techniques. The advantages of APC include the ability to reach lesions located lateral to the probe or around bends and corners that are not suitable for Nd:YAG laser therapy and electrocautery, as well as adequate hemostasis of the lesion (35-37). The complications associated with APC are similar to electrocautery, although a case of fatal air embolism has previously been reported (38). APC is not the best choice for removal of a bulky lesion, since it is less precise compared with other ablation techniques (30).

Cryotherapy causes cellular injury and death by exposing biological tissues to cycles of freezing and thawing. Multiple factors can influence the efficacy of cryotherapy, including the speed of freeze-thawing and the lowest temperature that the cryoprobe can achieve to destroy live tissue. Cryotherapy does not affect cartilage because of its low water content (39). Cryotherapy is used in the treatment of endobronchial tumors. Its advantages include a lower cost, fewer precautions and superior safety. Furthermore, it is less likely to cause complications such as perforation, malacia and cicatricial stricture (25). However, cryotherapy cannot be used to achieve immediate airway patency in patients with severe airway stenosis, owing to its delayed effect (40). In a previous study, the application of cryotherapy was extended by a technique that allowed immediate recanalization of obstructed airways affected by the extraction of large pieces of tumors (38). This involved using a probe that was able to rapidly freeze tissue and remove the entire tissue around the probe before the frozen tissue thawed. However, airway bleeding with the potential for massive hemorrhage is an important consideration, such that the safety of this new technique requires further investigation.

The present study demonstrated that the use of these ablation techniques at specific settings could cause similar biological effects. Nd:YAG laser therapy at $20 \mathrm{~W}$ for $1 \mathrm{sec}$, electrocautery at $40 \mathrm{~W}$ for $3 \mathrm{sec}, \mathrm{APC}$ at $40 \mathrm{~W}$ for $5 \mathrm{sec}$ and cryotherapy at $100 \Omega$ for $120 \mathrm{sec}$ resulted in identical pathological changes in the tracheal wall. These alterations included shedding necrotic mucosa, partial tracheal defects, submucosal coagulative necrosis and destruction of the superficial cartilage layer, with similar infiltration depths of tissue damage. Therefore, we propose that these specific settings are efficacy-equivalent values for these ablation techniques. This is important information for a number of institutes where only one or two endobronchial ablation modalities are available; most endobronchial therapies can be performed to achieve the desired results, even if the available equipment is limited.

It is important to note that fibrous scarring tissue is retractile and, once it loses cartilaginous support, iatrogenic secondary stenosis can develop (30). Verkindre et al (30) found that, after setting electrocautery to deliver 40 or $120 \mathrm{~W}$, coagulative necrosis and intense inflammation of the mucosa of early lesions extended deep into the cartilage layer, followed by formation of transmural fibrosis and the destruction of cartilage, which resulted in iatrogenic secondary stenosis. By mentioning this possibility, the authors do not question the clinical application of ablation techniques, but only want to alert physicians to the potential for iatrogenic secondary stenosis caused by extensive damage to the tracheal wall.

In conclusion, the present study demonstrated that the biological effects of various endobronchial ablation techniques on the trachea were a function of the power or impedance settings and application period, and that these techniques may be equally efficacious when applied using settings and application durations specific to each technique. Specifically, this study determined that the safe parametric values for endobronchial ablation with these techniques were $20 \mathrm{~W}$ for $\leq 1 \mathrm{sec}$ for Nd:YAG laser therapy, $40 \mathrm{~W}$ for $\leq 3 \mathrm{sec}$ for high-frequency electrocautery, $40 \mathrm{~W}$ at $\leq 5 \mathrm{sec}$ for APC and $100 \Omega$ for $\leq 120 \mathrm{sec}$ for $\mathrm{CO}_{2}$ cryotherapy. The results of the present study may serve as a reference for the clinical application of endobronchial ablation techniques.

\section{Acknowledgements}

The authors would like to thank Medjaden Bioscience for assisting in the preparation of this manuscript. This work was supported by Science and Technology Commission of Shanghai Municipality (grant no. 134119a0302).

\section{References}

1. Bhamra-Ariza P, Keogh AM and Muller DW: Percutaneous interventional therapies for the treatment of patients with severe pulmonary hypertension. J Am Coll Cardiol 63: 611-618, 2014.

2. Andersen PE and Kjeldsen AD: Interventional treatment of pulmonary arteriovenous malformations. World J Radiol 2: 339-344, 2010.

3. Keogh AM, Mayer E, Benza RL, Corris P, Dartevelle PG, Frost AE, Kim NH, Lang IM, Pepke-Zaba J and Sandoval J: Interventional and surgical modalities of treatment in pulmonary hypertension. J Am Coll Cardiol 54 (Suppl 1): S67-S77, 2009.

4. Gudausky TM and Beekman RH III: Current options and long-term results for interventional treatment of pulmonary valvar stenosis. Cardiol Young 16: 418-427, 2006.

5. Mantovani G, Astara G, Manca G, Versace R, Contu P and Carai A: Endoscopic laser ablation as palliative treatment of endobronchial, nonresectable, or recurrent lung cancer: Assessment of its impact on quality of life. Clin Lung Cancer 1: 277-285; discussion 286, 2000.

6. Taber SW, Buschemeyer WC III, Fingar VH and Wieman TJ: The treatment of malignant endobronchial obstruction with laser ablation. Surgery 126: 730-733; discussion 733-735, 1999.

7. Chua AP and Mehta AC: Barotrauma from novel endobronchial ablation techniques. J Bronchology Interv Pulmonol 16: 75-77, 2009.

8. Manali ED, Stathopoulos GT, Gildea TR, Fleming P, Thornton J Xu M, Papiris SA, Mehta AC and Mughal MM: High dose-rate endobronchial radiotherapy for proximal airway obstruction due to lung cancer: 8-year experience of a referral center. Cancer Biother Radiopharm 25: 207-213, 2010.

9. Chen Y, Wang WJ and Wang HF: Therapeutic effect of tracheal anastomosis versus interventional bronchoscopy in the treatment of airway stenosis. Nan Fang Yi Ke Da Xue Xue Bao 30: 1359-1362, 2010 (In Chinese).

10. Li Y, Yao XP, Bai C, Huang Y, Wang Q, Zhao LJ, Dong YC, Teng HY and Li Q: Therapeutic efficacy analysis of bronchoscopic interventional therapy on severe tuberculous main bronchial stenosis complicated with unilateral atelectasis. Zhonghua Jie He He Hu Xi Za Zhi 34: 454-458, 2011 (In Chinese).

11. Zhang J, Wang J, Wang T, Xu M, Dang BW, Pei Y H and Zhang CY: A pilot study on interventional bronchoscopy in the management of airway stenosis with benign hyperplasia. Zhonghua Jie $\mathrm{He} \mathrm{He}$ Hu Xi Za Zhi 34: 334-338, 2011 (In Chinese).

12. Ost DE, Ernst A, Grosu HB, Lei X, Diaz-Mendoza J, Slade M, Gildea TR, Machuzak M, Jimenez CA, Toth J, et al: Therapeutic bronchoscopy for malignant central airway obstruction: success rates and impact on dyspnea and quality of life. Chest 147: 1282-1298, 2015.

13. Saji H, Furukawa K, Tsutsui H, Tsuboi M, Ichinose S, Usuda J, Ohira T and Ikeda N: Outcomes of airway stenting for advanced lung cancer with central airway obstruction. Interact Cardiovasc Thorac Surg 11: 425-428, 2010. 
14. Beamis JF Jr: Interventional pulmonology techniques for treating malignant large airway obstruction: An update. Curr Opin Pulm Med 11: 292-295, 2005

15. Jones GS and Baldwin DR: Lung cancer screening and management. Minerva Med 106: 339-354, 2015.

16. Colt HG and Murgu SD: Interventional bronchoscopy from bench to bedside: New techniques for early lung cancer detection. Clin Chest Med 31: 29-37, 2010.

17. Pasic A, Brokx HAP, Noordegraaf AV, Paul RMA, Postmus PE and Sutedja TG: Cost-effectiveness of early intervention: Comparison between intraluminal bronchoscopic treatment and surgical resection for T1N0 lung cancer patients. Respiration 71: 391-396, 2004.

18. Morrison SA, Hill SL, Rogers GS and Graham RA: Efficacy and safety of continuous low-irradiance photodynamic therapy in the treatment of chest wall progression of breast cancer. J Surg Res 192: 235-241, 2014

19. Simone CB II, Friedberg JS, Glatstein E, Stevenson JP, Sterman DH, Hahn SM and Cengel KA: Photodynamic therapy for the treatment of non-small cell lung cancer. J Thorac Dis 4: 63-75, 2012.

20. Bai C, Dong YC, Song XL, Huang Y, Shi H, Hu ZL and Li Q In vitro study of safety and co-efficiency of the transbronchial coagulation techniques. Chin Med J (Engl) 126: 124-128, 2013.

21. Zhikai Z, Lizhi N, Liang Z, Jianying Z, Fei Y, Jibing C, Jialiang $L$ and Kecheng $X$ : Treatment of central type lung cancer by combined cryotherapy: Experiences of 47 patients. Cryobiology 67: 225-229, 2013.

22. Schumann C, Hetzel M, Babiak AJ, Hetzel J, Merk T, Wibmer T, Lepper PM and Krüger S: Endobronchial tumor debulking with a flexible cryoprobe for immediate treatment of malignant stenosis. J Thorac Cardiovasc Surg 139: 997-1000, 2010.

23. Rojas-Tula DG, Gómez-Fernández M, García-López JJ Cobos-Ceballos MJ, Gil-Fuentes A, Pérez-Laya JM, Serrano-Rebollo JC, Ortega-González A, Vargas-Hidalgo T, Ruíz de Oña-Lacasta JM and Celdrán-Gil J: Endobronchial cryotherapy for a mycetoma. J Bronchology Interv Pulmonol 20: 330-332, 2013

24. Mu D, Nan D, Li W, Fu E, Xie Y, Liu T and Jin F: Efficacy and safety of bronchoscopic cryotherapy for granular endobronchial tuberculosis. Respiration 82: 268-272, 2011.

25. Lee SH, Choi WJ, Sung SW, Kim YK, Kim CH, Zo JI and Park KJ: Endoscopic cryotherapy of lung and bronchial tumors: A systematic review. Korean J Intern Med 26: 137-144, 2011.

26. Fitzmaurice GJ, Redmond KC, Fitzpatrick DA and Bartosik W: Endobronchial cryotherapy facilitates end-stage treatment options in patients with bronchial stenosis: A case series. Ann Thorac Med 9: 120-123, 2014.

27. Lai JP, Tao ZD, Xiao JY, Chen XH, Zhao SP, Tian YQ and Betz CS: Microinvasive Nd:YAG laser therapy of early glottic carcinoma and its effect on soluble interleukin-2 receptor, interleukin-2 and natural killer cells. Laryngoscope 111: 1585-1588, 2001.
28. Hermes A, Heigener D, Gatzemeier U, Schatz J and Reck M: Efficacy and safety of bronchoscopic laser therapy in patients with tracheal and bronchial obstruction: A retrospective single institution report. Clin Respir J 6: 67-71, 2012.

29. Wahidi MM, Unroe MA, Adlakha N, Beyea M and Shofer SL: The use of electrocautery as the primary ablation modality for malignant and benign airway obstruction. J Thorac Oncol 6: 1516-1520, 2011.

30. Verkindre C, Brichet A, Maurage CA, Ramon P, Homasson JP and Marquette $\mathrm{CH}$ : Morphological changes induced by extensive endobronchial electrocautery. Eur Respir J 14: 796-799, 1999

31. Sindhwani G, Rawat J and Keserwani V: Role of endobronchial electrocautery in management of neoplastic central airway obstruction: Initial experience with seven cases. Indian J Chest Dis Allied Sci 54: 165-168, 2012.

32. Rolle A, Pereszlenyi A, Koch R, Richard M and Baier B: Is surgery for multiple lung metastases reasonable? A total of 328 consecutive patients with multiple-laser metastasectomies with a new 1318-nm Nd:YAG laser. J Thoracic Cardiovasc Surg 131: 1236-1242, 2006

33. Seaman JC and Musani AI: Endobronchial ablative therapies. Clin Chest Med 34: 417-425, 2013.

34. Nikfarjam M, Muralidharan V, Malcontenti-Wilson C, McLaren W and Christophi C: Impact of blood flow occlusion on liver necrosis following thermal ablation. ANZ J Surg 76: 84-91, 2006.

35. Reddy C, Majid A, Michaud G, Feller-Kopman D, Eberhardt R, Herth F and Ernst A: Gas embolism following bronchoscopic argon plasma coagulation: A case series. Chest 134: 1066-1069, 2008.

36. Jin F, Mu D, Xie Y, Fu E and Guo Y: Application of bronchoscopic argon plasma coagulation in the treatment of tumorous endobronchial tuberculosis: Historical controlled trial. J Thorac Cardiovasc Surg 145: 1650-1653, 2013.

37. Bolliger CT, Sutedja TG, Strausz J and Freitag L: Therapeutic bronchoscopy with immediate effect: Laser, electrocautery, argon plasma coagulation and stents. Eur Respir J 27: 1258-1271, 2006.

38. Boujaoude Z, Young D, Lotano R and Abouzgheib W: Cryosurgery for the immediate treatment of acute central airway obstruction. J Bronchology Interv Pulmonol 20: 45-47, 2013.

39. Yu CH, Lin HP, Cheng SJ, Sun A and Chen HM: Cryotherapy for oral precancers and cancers. J Formos Med Assoc 113: 272-277, 2014.

40. Vergnon JM, Huber RM and Moghissi K: Place of cryotherapy, brachytherapy and photodynamic therapy in therapeutic bronchoscopy of lung cancers. Eur Respir J 28: 200-218, 2006. 